Archive for

Organic Chemistry

Arkivoc 2018, part ii, 192-204

\title{
Photochemical [2+2] cycloaddition reaction of enone derivatives with 2-siloxy-1H-pyrrole derivatives
}

\author{
Jianfei Xue, ${ }^{a}$ Ryukichi Takagi, ${ }^{a}$ and Manabu Abe*a,b \\ a. Department of Chemistry, Graduate School of Science, Hiroshima University \\ ${ }^{b}$ Hiroshima Research Centre for Photo-Drug-Delivery Systems \\ a,b 1-3-1 Kagamiyama, Higashi-Hiroshima, Hiroshima 739-8526, Japan \\ Email: mabe@hiroshima-u.ac.jp
}

This paper is dedicated to Professor Kenneth Laali on the occasion of his 65th birthday

Received 08-18-2017

Accepted 10-31-2017

Published on line 12-03-2017

\section{Abstract}

The regio- and stereo-selectivity of the photochemical [2+2] cycloaddition reaction of 2-(t-butyldimethylsilyloxy)-1H-pyrrole with enone derivatives are investigated. Regioselective formation of cyclobutanes was found in the intermolecular photochemical [2+2] cycloaddition reaction of the pyrrole derivative with cyclopentenone. In contrast, an oxetane rather than a cyclobutane product was selectively formed when 1,4naphthoquinone was used as the enone. The reaction conditions were optimized to obtain the cycloadducts in high yields.

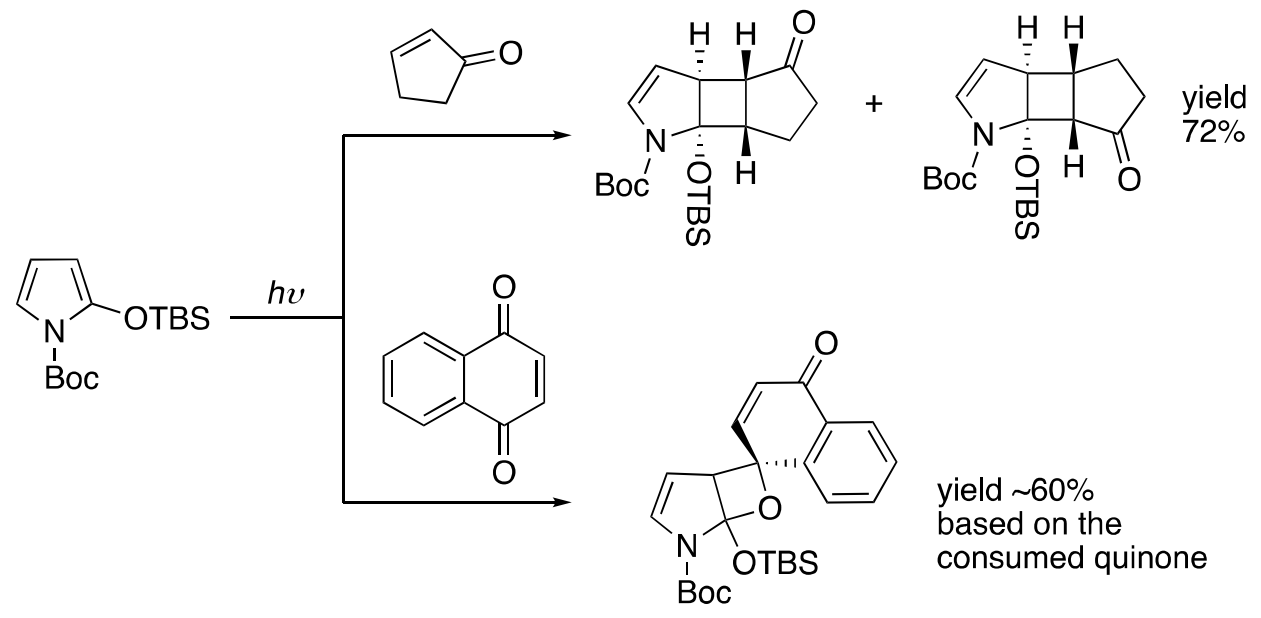

Keywords: Photochemical [2+2] cycloadditions, pyrroles, enones, cyclobutanes, oxetane 


\section{Introduction}

The strained cyclobutane $e^{1-20}$ and oxetane $e^{21-23}$ structures are important in organic synthesis. After Ciamician discovered the first example of photochemical [2+2] cycloaddition reaction, ${ }^{24}$ Paternò, following Ciamician, reported the first photochemical $[2+2]$ oxetane formation reaction using light irradiation. ${ }^{25}$ Since then, many chemists have contributed their efforts to the synthetic and mechanistic studies of photochemical $[2+2]$ cycloaddtion reactions. ${ }^{1-9}$ Generally, the photochemical [2+2] oxetane formation reactions are called PaternòBüchi (PB) reactions, in which furan derivatives have played their significant roles as alkene substrates. ${ }^{21-23}$ To our best knowledge, even though a series of work concerning intramolecular photochemical [2+2] cycloaddition reaction of pyrrole derivatives have been achieved, ${ }^{26-28,34}$ very few reports on the intermolecular case have been found till now. ${ }^{29-34}$ Besides pyrrole derivatives, many examples of the photochemical cyclobutane formations have been reported from pyrrolone $e^{31-34}$ and indole ${ }^{35-41}$ compounds. Recently, the regioselective spirocyclic oxetane product (3) has been successfully isolated by us using the PB reaction of 2silyloxy-1H-pyrrole 1 with benzophenone (2) in high yields (Scheme 1). The regioselective formation of oxetane 3 was rationalized by the intervention of the corresponding triplet diradical intermediate. ${ }^{42}$

In the present study, the photochemical reactions of $\mathbf{1}$ with enone derivatives $\mathbf{4}$ and $\mathbf{5}$ were investigated to understand their product selectivity, cyclobutane versus oxetane, their regioselectivity, and stereoselectivity (Scheme 1). Interestingly, bicyclic cyclobutanes 6 and $\mathbf{7}$ were isolated in total 72\% yield in the reaction with cyclopentenone 4 . In contrast to the selective formation of cyclobutanes, oxetane 8 was formed in $~ 60 \%$ yield in the photochemical reaction with 1,4-naphthoquinone (5). The regioselective bond formation at the C2 position was found to be different from the regioselectivity promoted by Lewis acid catalyzed thermal reactions, in which the bond formation reaction occurs selectively at C5 position of the pyrrole derivative (Scheme 1). ${ }^{43}$

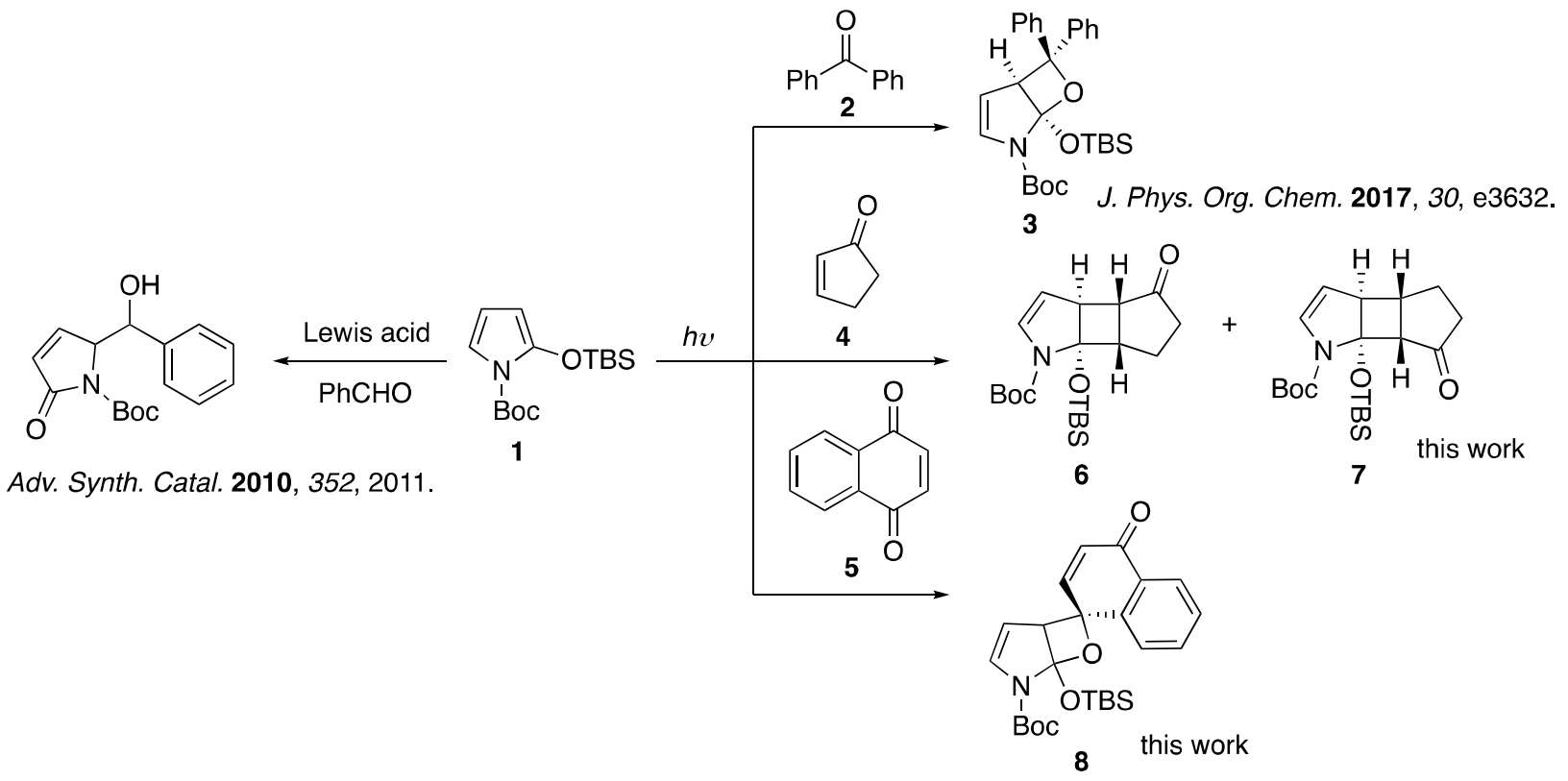

Scheme 1. Regiselectivity of Lewis-acid promoted reactions and photochemical [2+2] cycloaddition reaction of 2-silyloxypyrrole 1 with carbonyl compounds. 


\section{Results and Discussion}

The pyrrole 2-(t-butyldimethylsilyloxy)- $N$ - $t$-butoxycarbonylpyrrole (1) was prepared from the corresponding lactam according to the literature. ${ }^{43}$ Firstly, the reaction mixture of $1(0.51 \mathrm{M})$ and $4(0.34 \mathrm{M})$ was irradiated by $365 \mathrm{~nm}$ using light-emitting diode (LED) at room temperature in a sealed Pyrex NMR tube in acetone- $d_{6}$ after the deoxygenation by 20 minutes nitrogen bubbling. According to the NMR spectroscopic analysis of the reaction mixture after 24 hours irradiation (Figure 1e), newly appeared signals at $\delta 6.8,3.5-2.0$ were assigned to the products 6 and 7 . After removing the solvent under reduced pressure, the products 6 and 7 were isolated in $12 \%$ yield with 64 : 36 isomer ratio by silica gel chromatography (entry 1 in Table 1).

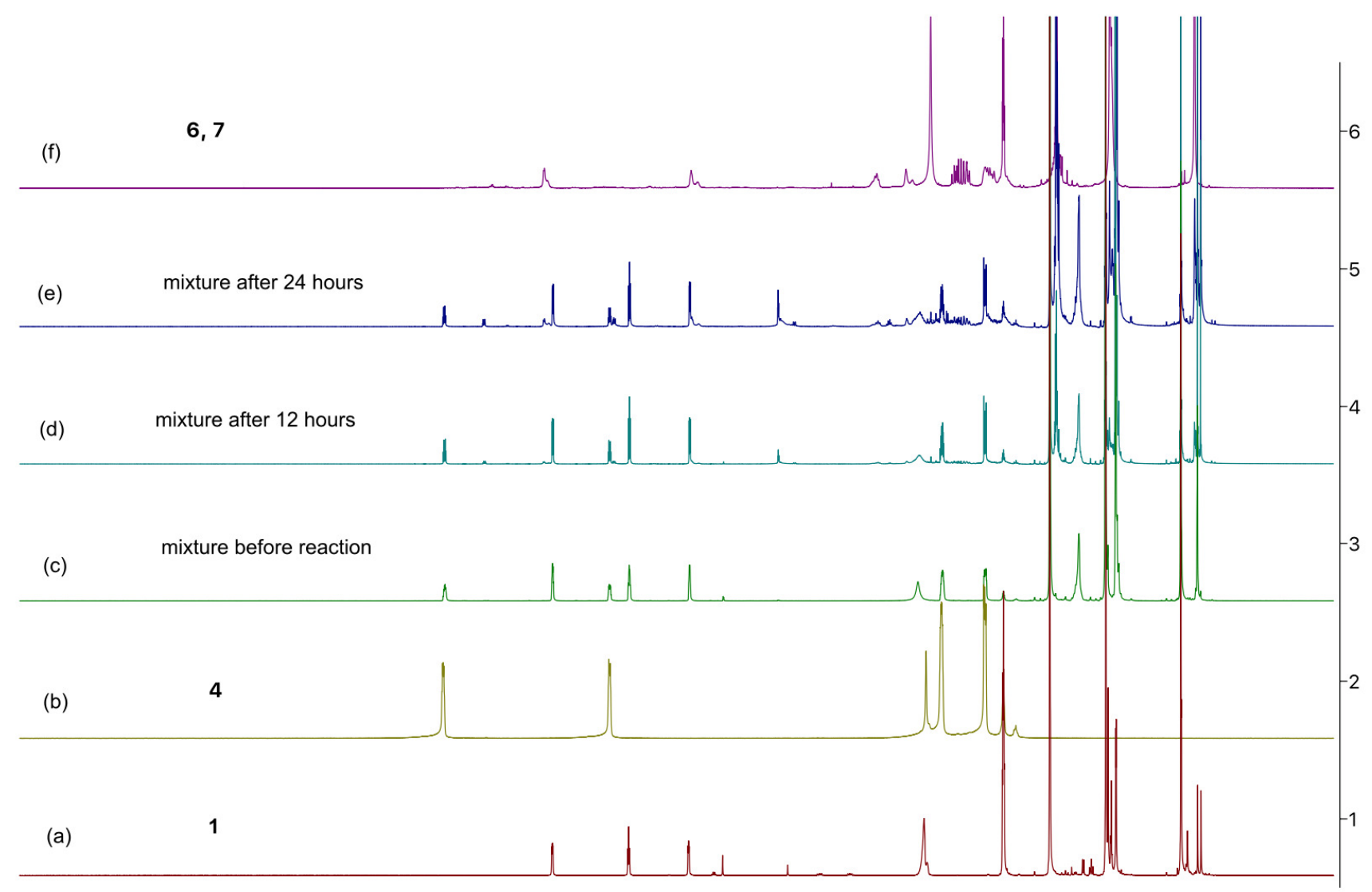

$\begin{array}{lllllllllllllllllllllllllll}12.0 & 11.5 & 11.0 & 10.5 & 10.0 & 9.5 & 9.0 & 8.5 & 8.0 & 7.5 & 7.0 & 6.5 & 6.0 & \begin{array}{c}5.5 \\ \mathrm{f}(\mathrm{ppm})\end{array} 5.0 & 4.5 & 4.0 & 3.5 & 3.0 & 2.5 & 2.0 & 1.5 & 1.0 & 0.5 & 0.0 & -0.5 & -1.0\end{array}$

Figure 1. ${ }^{1} \mathrm{H}$ NMR (400 MHz, acetone- $d_{6}$ ) spectroscopic analysis of the photochemical [2+2] cycloaddition reaction of 1 and 4 under irradiation at $365 \mathrm{~nm}$. (a) 1, (b) 4, (c) before irradiation at r. t., (d) after 12 hours of irradiation, (e) after 24 hours of irradiation, (f) isolated compounds $\mathbf{6}$ and $\mathbf{7}$.

The structures of 6 and 7 were confirmed by 1D-NMR and 2D-NMR spectroscopic analyses, i.e. ${ }^{1} \mathrm{H},{ }^{13} \mathrm{C}, \mathrm{H}-\mathrm{H}$ COSY, H-C HSQC, H-C HMBC, H-H NOESY, and high-resolution mass spectroscopic analysis. The formation of further regioisomers 9 and 10 was excluded by the observed two vinyl protons $H_{a}$ and $H_{b}$ at $6.75,6.60$ ppm and 5.15, $5.07 \mathrm{ppm}$, respectively, in the formed cycloadducts (Figures 2 and 3 ). Because the two protons, $\mathrm{H}_{a}(\delta$ $6.75,6.60)$ and $H_{b}(\delta 5.16,5.09)$, were correlated with the $s^{2}$ carbons $(\delta 132.34,132.32,107.4,107.0)$, the two protons at $\sim 6.7$ and $\sim 5.1 \mathrm{ppm}$ were assigned to the vinylic protons (Figure 3). In the H-C HMBC spectrum 
(Figure 4), the correlation of $\mathrm{H}_{d}(\delta 2.98)$ and the cyclic carbonyl carbon ( $\left.\delta 219.7\right)$ was observed in the major isomer of the products, indicating that the major product was the tricyclic cyclobutane 6.

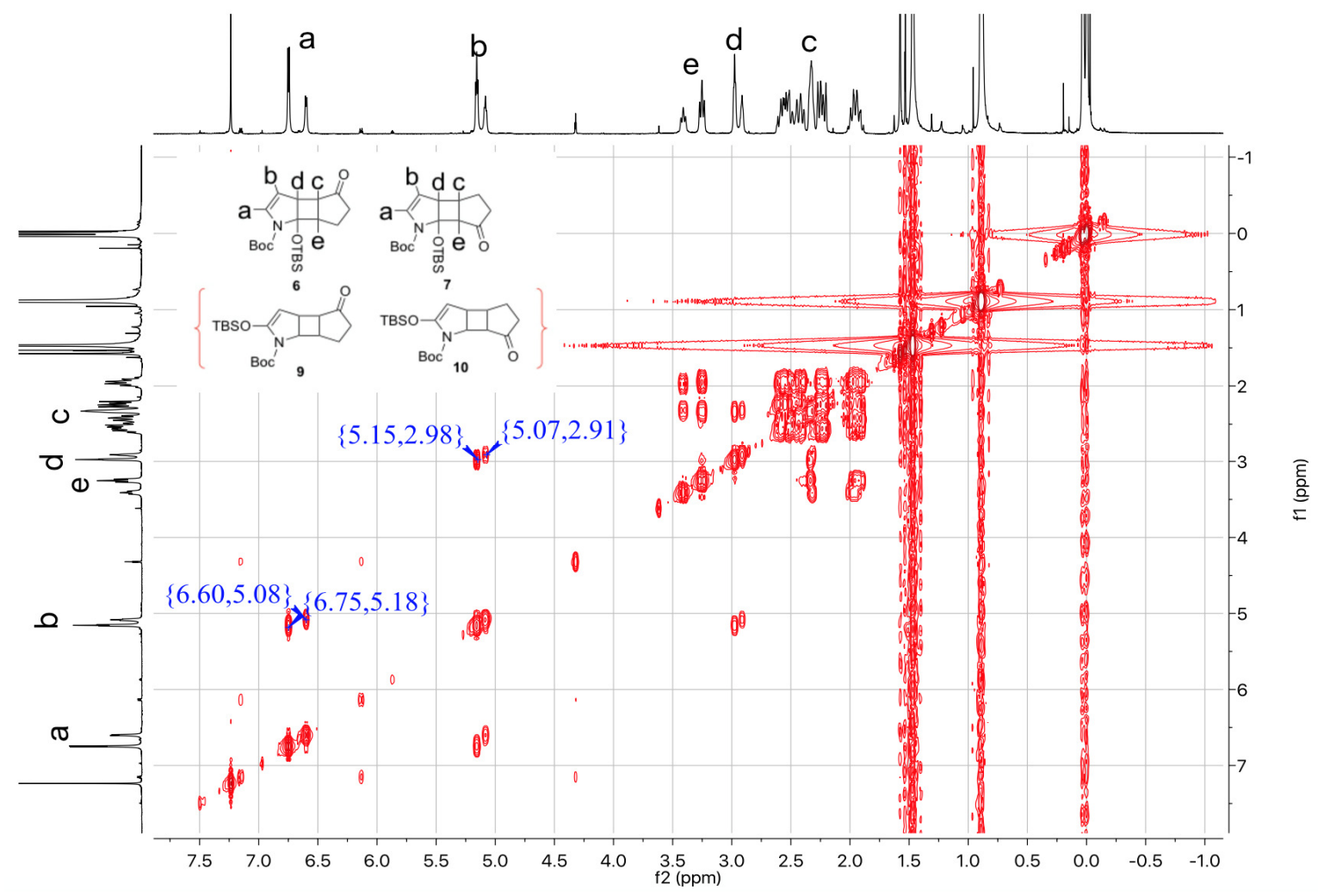

Figure 2. $\mathrm{H}-\mathrm{H}$ COSY spectrum of a mixture of 6 and $7\left(400 \mathrm{MHz}, \mathrm{CDCl}_{3}\right)$.

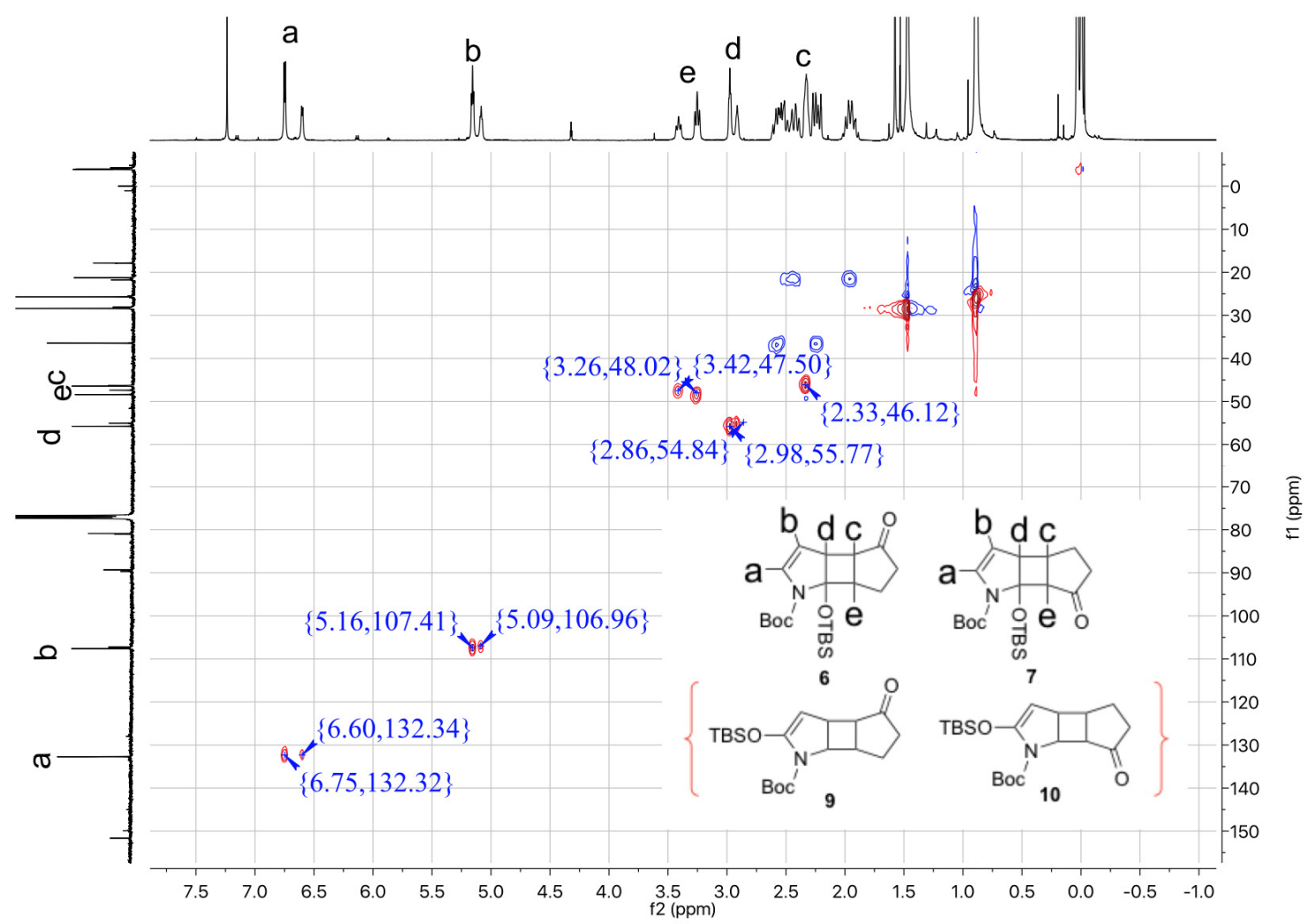

Figure 3. $\mathrm{H}-\mathrm{C} \mathrm{HSQC}$ spectrum of a mixture of 6 and $7\left(400 \mathrm{MHz}, \mathrm{CDCl}_{3}\right)$. 


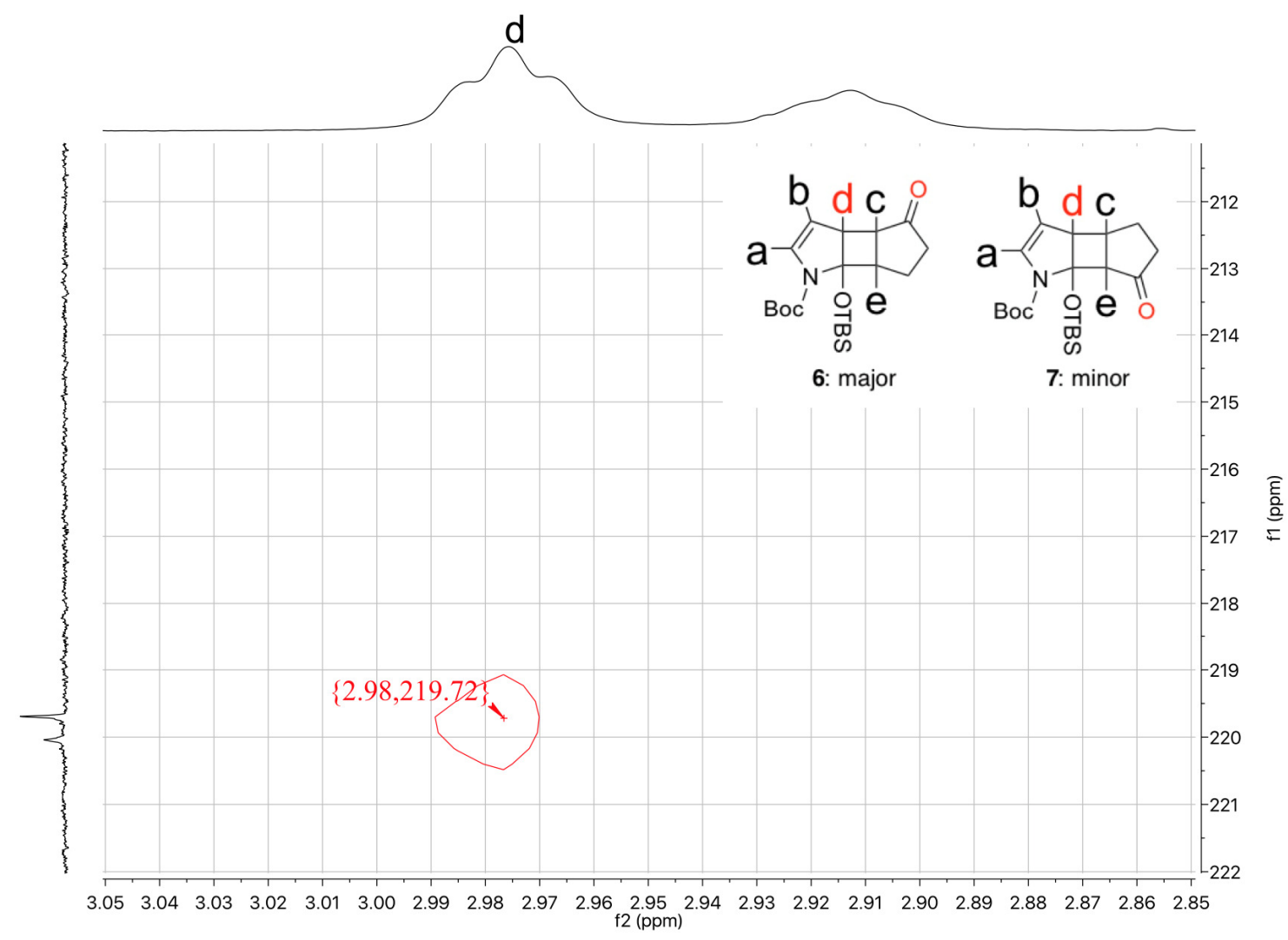

Figure 4. $\mathrm{H}-\mathrm{C} \mathrm{HMBC}$ spectrum of a mixture of 6 and $7\left(400 \mathrm{MHz}, \mathrm{CDCl}_{3}\right)$.

The stereochemistry of compounds 6 and 7, exo versus endo, was determined by their 2D-NOESY spectroscopic analyses (Figure 5). Thus, the correlations between $\mathrm{H}_{b}(\delta 5.20,5.13)$ and $\mathrm{H}_{c}(\delta 2.38,2.37)$ were observed in the H-H NOESY spectrum, indicating that both compounds 6 and 7 possess the exo-configuration as shown in Figure 5.

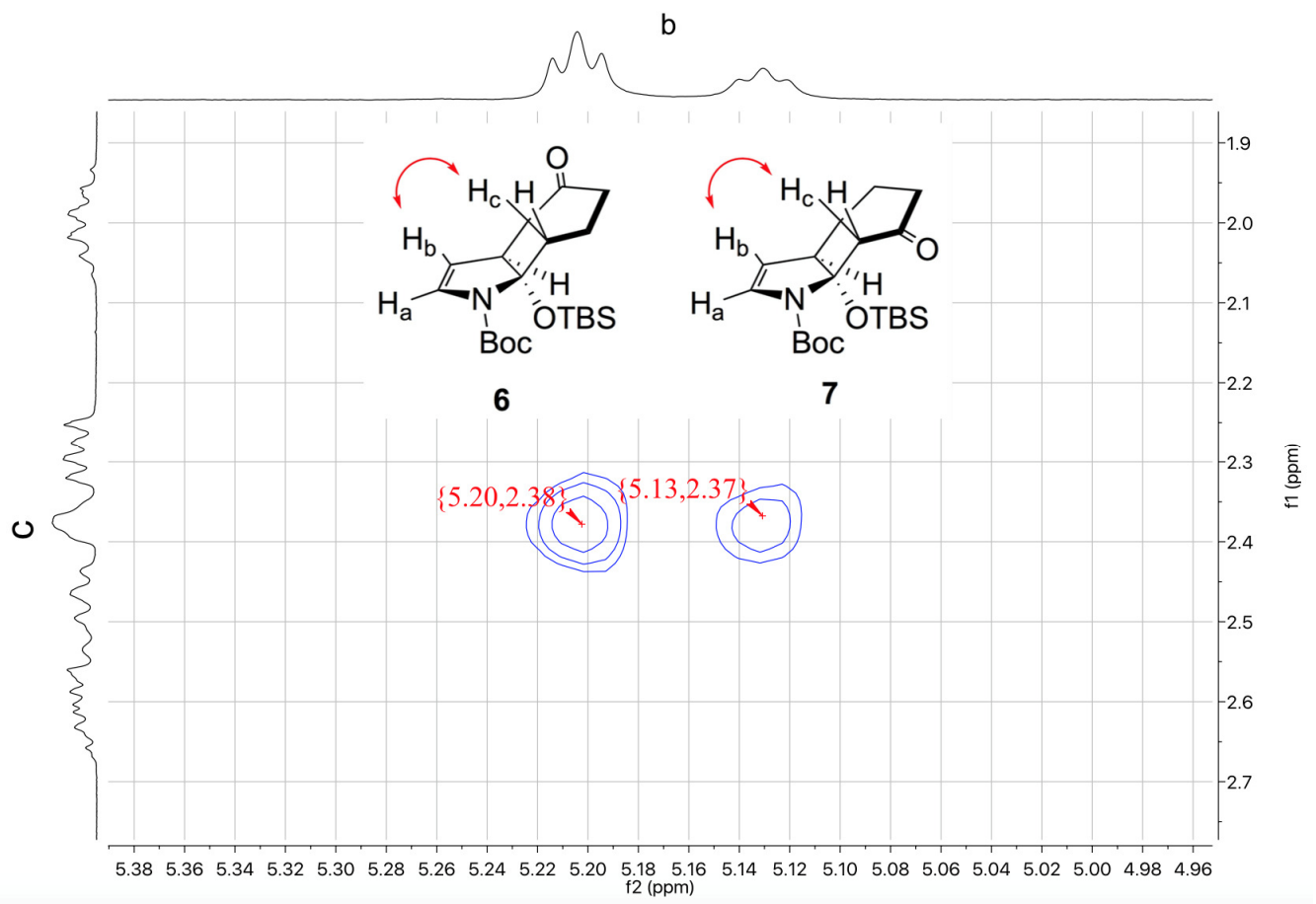

Figure 5. $\mathrm{H}-\mathrm{H}$ NOESY spectrum of a mixture of 6 and $7\left(400 \mathrm{MHz}, \mathrm{CDCl}_{3}\right)$. 
The reaction conditions were optimized to obtain $\mathbf{6}$ and $\mathbf{7}$ in high yields, because the large amount of enone $\mathbf{4}$ was recovered under the conditions in entry 1 (Table 1). The ratio of compound $\mathbf{1}$ and $\mathbf{4}$ dramatically influenced the conversion of compound $\mathbf{4}$ to give high yields of compounds 6 and $\mathbf{7}$ (entries 1-4, Table 1). When a large excess of compound 1 (15 equiv) was used for the photochemical reaction with $4,72 \%$ of compounds 6 and $\mathbf{7}$ were obtained after $24 \mathrm{~h}$ using $365 \mathrm{~nm}$-LED in acetone (entry 4). The yield of adducts 6 and 7 decreased when acetonitrile or benzene was used as a solvent. (entries 5 and 6 , Table 1), indicating the reaction occurs in the triplet excited state. The product ratio of 6 and 7, 65:35, was not affected by the concentration or solvent (Table 1).

Table 1. Photochemical reaction of 1 with cyclopentenone $(4)^{\mathrm{a}}$

\begin{tabular}{|c|c|c|c|c|c|}
\hline Entry & {$[1] / \mathrm{mM}$} & {$[4] / \mathrm{mM}$} & $\begin{array}{c}\text { Recovered } \\
\text { enone } 4\end{array}$ & $6: 7$ & Yields of $6+\mathbf{7}^{b}$ \\
\hline 1 & 510 & 340 & $73 \%$ & $64: 36$ & $12 \%$ \\
\hline 2 & 213 & 42.5 & $31 \%$ & $66: 34$ & $57 \%$ \\
\hline 3 & 425 & 42.5 & $30 \%$ & $63: 37$ & $64 \%$ \\
\hline 4 & 638 & 42.5 & $16 \%$ & $65: 35$ & $72 \%$ \\
\hline $5^{c}$ & 638 & 42.5 & $58 \%$ & $62: 38$ & $29 \%$ \\
\hline $6^{d}$ & 638 & 42.5 & $27 \%$ & $64: 36$ & $57 \%$ \\
\hline
\end{tabular}

${ }^{\text {a }}$ Acetone was used for the reaction solvent. A light-emitting diode lamp at $365 \mathrm{~nm}$ was used for 24 hours irradiation; ${ }^{b}$ Isolation yield after silica gel chromatography; ${ }^{c}$ Acetonitrile was used for solvent; ${ }^{d}$ Benzene was used for solvent.

Table 2. Optimization of the reaction conditions of 1 and 1,4-naphthoquinone (5) ${ }^{\mathrm{a}}$

\begin{tabular}{|c|c|c|c|c|}
\hline Entry & {$[1] / \mathrm{mM}$} & {$[5] / \mathrm{mM}$} & $\begin{array}{c}\text { Yield of } \\
8^{b}\end{array}$ & $\begin{array}{c}\text { yield based on } \\
\text { conversion }^{c}\end{array}$ \\
\hline $1^{d}$ & 1020 & 340 & $17 \%$ & $26 \%$ \\
\hline 2 & 1020 & 340 & $29 \%$ & $59 \%$ \\
\hline 3 & 510 & 340 & $22 \%$ & $36 \%$ \\
\hline 4 & 340 & 340 & $24 \%$ & $47 \%$ \\
\hline 5 & 227 & 340 & $26 \%$ & $40 \%$ \\
\hline 6 & 113 & 340 & $13 \%$ & $16 \%$ \\
\hline $7^{d}$ & 638 & 42.5 & 0 & 0 \\
\hline $8^{\mathrm{e}}$ & 510 & 340 & 0 & 0 \\
\hline
\end{tabular}

${ }^{\text {a }}$ Benzene was used for the reaction solvent. A high pressure Hg lamp (300 W) was used for 6 hours irradiation; ${ }^{b}$ Isolation yield after silica gel chromatography; ${ }^{\mathrm{c}}$ The yield was calculated based on the consumed naphthoquinone by ${ }^{1} \mathrm{H}$ NMR analysis using $\mathrm{Ph}_{3} \mathrm{CH}$ as internal standard; ${ }^{d}$ Light-emitting diode lamp at $365 \mathrm{~nm}$ was used for light resource; ${ }^{\mathrm{e}}$ Acetone was used as solvent. 
Next, the photochemical reaction of naphthoquinone (5) with 1 was conducted under the similar reaction conditions (Scheme 1, Table 2). In general, regarding the product selectivity, cyclobutane versus oxetane, mixtures of oxetane and cyclobutane were formed in the photochemical cycloaddition reactions reported previously. ${ }^{44-50}$ However, on irradiation of $\mathbf{1}$ with $\mathbf{5}$ the formation of the oxetane product $\mathbf{8}$ was observed, and the alternative possible cyclobutane products were not observed in the photo-reaction.

The high pressure Hg lamp (300W) through Pyrex filter was found to be better light source than the 365 $\mathrm{nm}$ LED lamp for the reaction (entries 1,2, Table 2). The chemical yield of compound 8 was largely dependent upon the compound ratio of $\mathbf{1 / 5}$ and solvent. When the excess amount of compound 1 was used for the reaction (entries 2-4), the conversion yield of $\mathbf{8}$ was higher than that for the reaction with excess amount of compound 5 (entries 5,6). Acetone was inappropriate for this PB reaction of $\mathbf{1}$ and $\mathbf{5}$ (entry 8).

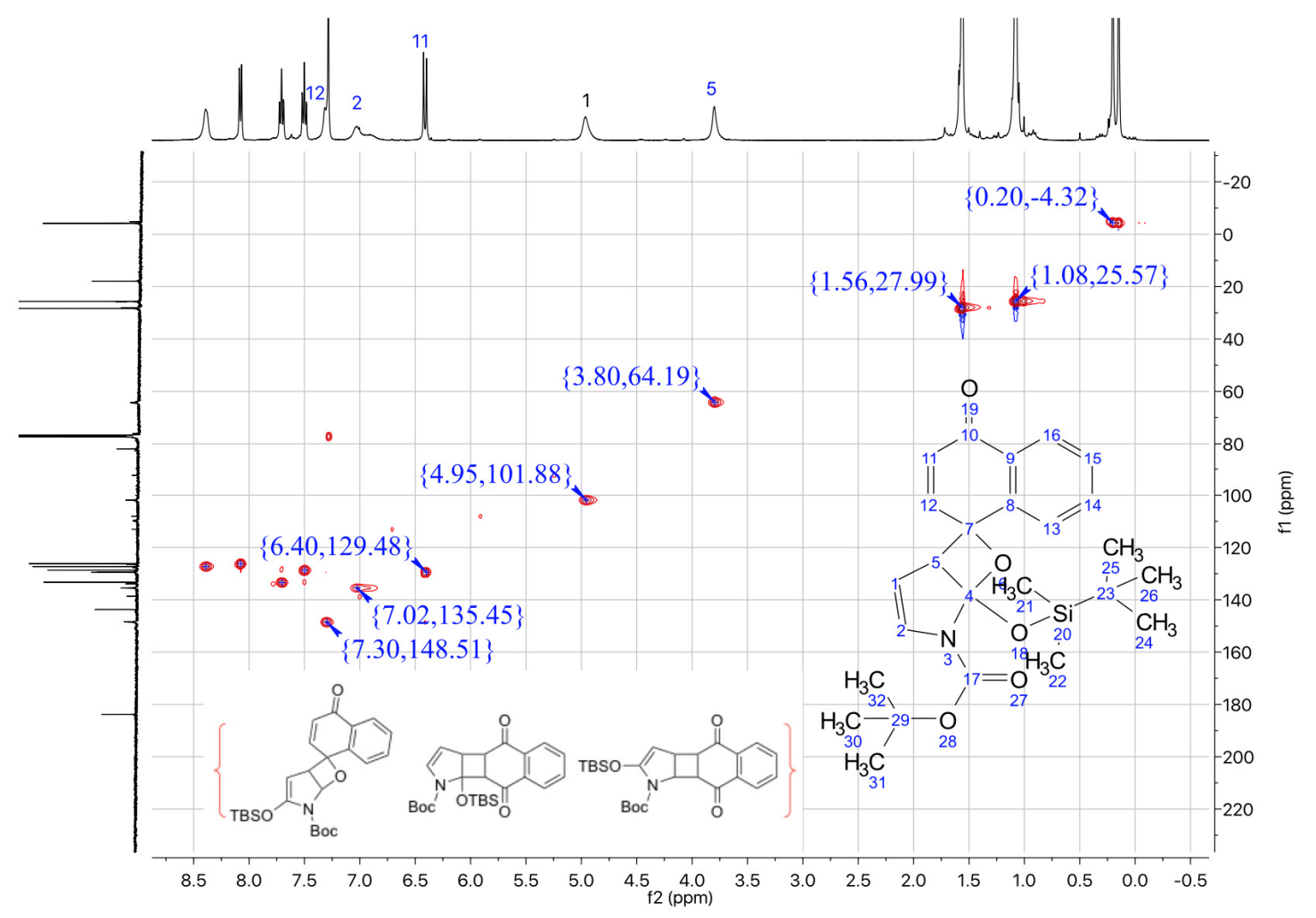

Figure 6. $\mathrm{H}-\mathrm{C} \mathrm{HSQC}$ spectrum of $8\left(400 \mathrm{MHz}^{\mathrm{C}} \mathrm{CDCl}_{3}\right)$.

The structure of oxetane 8 was confirmed by the measurement of 1D, 2D NMR and HRMS spectra. Except the protons of the Boc and silyloxy groups, only one aliphatic proton $\mathrm{H}_{5}$ at $\delta 3.80$ was observed in the isolated product, which was correlated to the $\mathrm{sp}^{3}$ carbon at $\delta 64.19$ according to $\mathrm{H}-\mathrm{C}$ HSQC spectrum (Figure 6). In addition, the findings of correlation of $\mathrm{H}_{1}$ and $\mathrm{H}_{2}$ and correlation of $\mathrm{H}_{1}$ and $\mathrm{H}_{5}$ in $\mathrm{H}-\mathrm{H}$ COSY spectrum could also exclude the possibilities of regioisomers (Figure 7). The observation excludes the possibility of the formation of cyclobutanes and the regioisomeric oxetane shown in Figure. 6. In addition to the spectroscopic evidence, only one carbonyl carbon at $\delta 183.9$ was found in the photochemical product which is correlated to $\mathrm{H}_{16}(\delta 8.09)$ and $\mathrm{H}_{12}(\delta 7.30)$ that also could exclude the possibility of a cyclobutane adduct (Figure 8). 


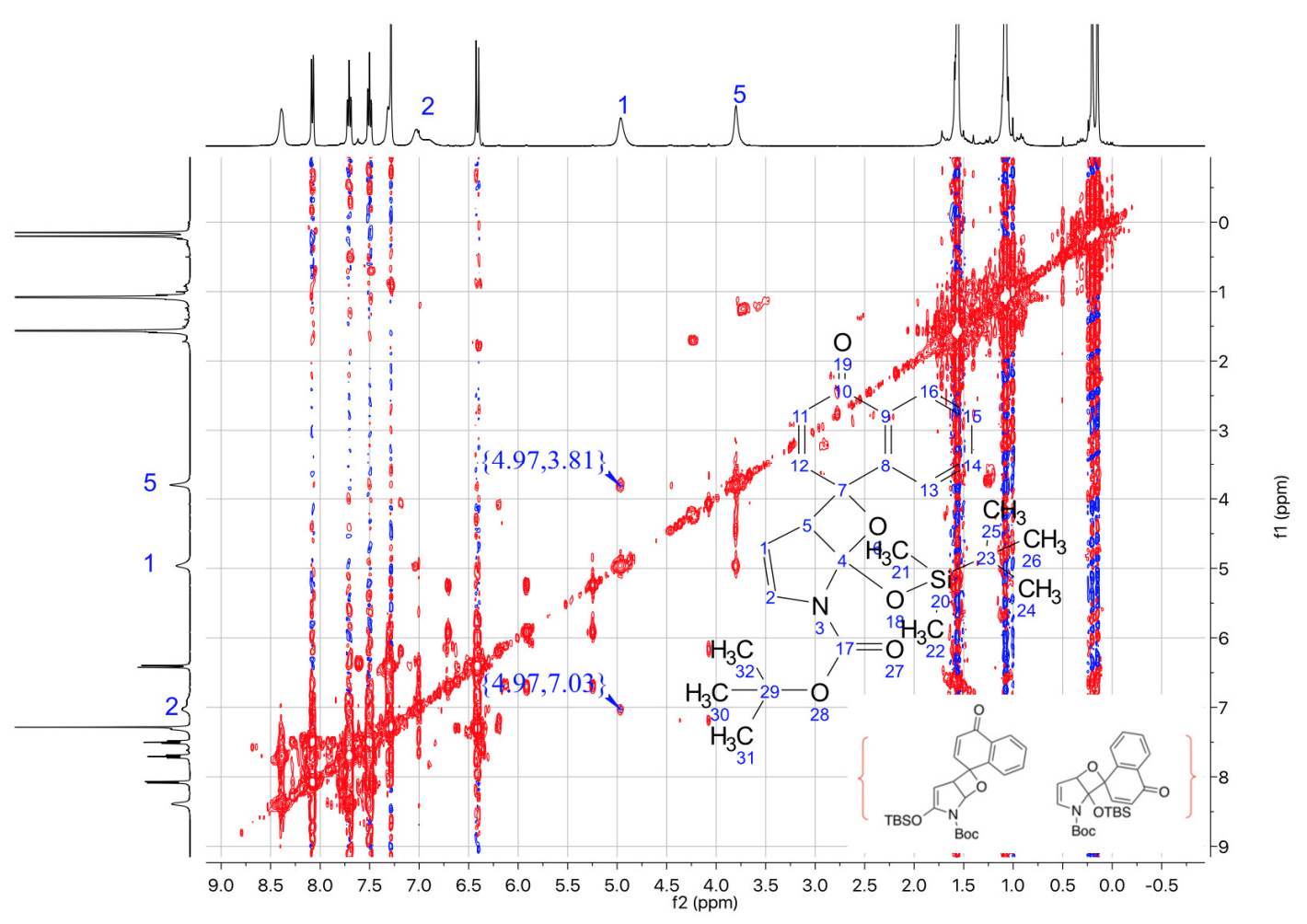

Figure 7. $\mathrm{H}-\mathrm{H}$ COSY spectrum of $8\left(400 \mathrm{MHz}, \mathrm{CDCl}_{3}\right)$

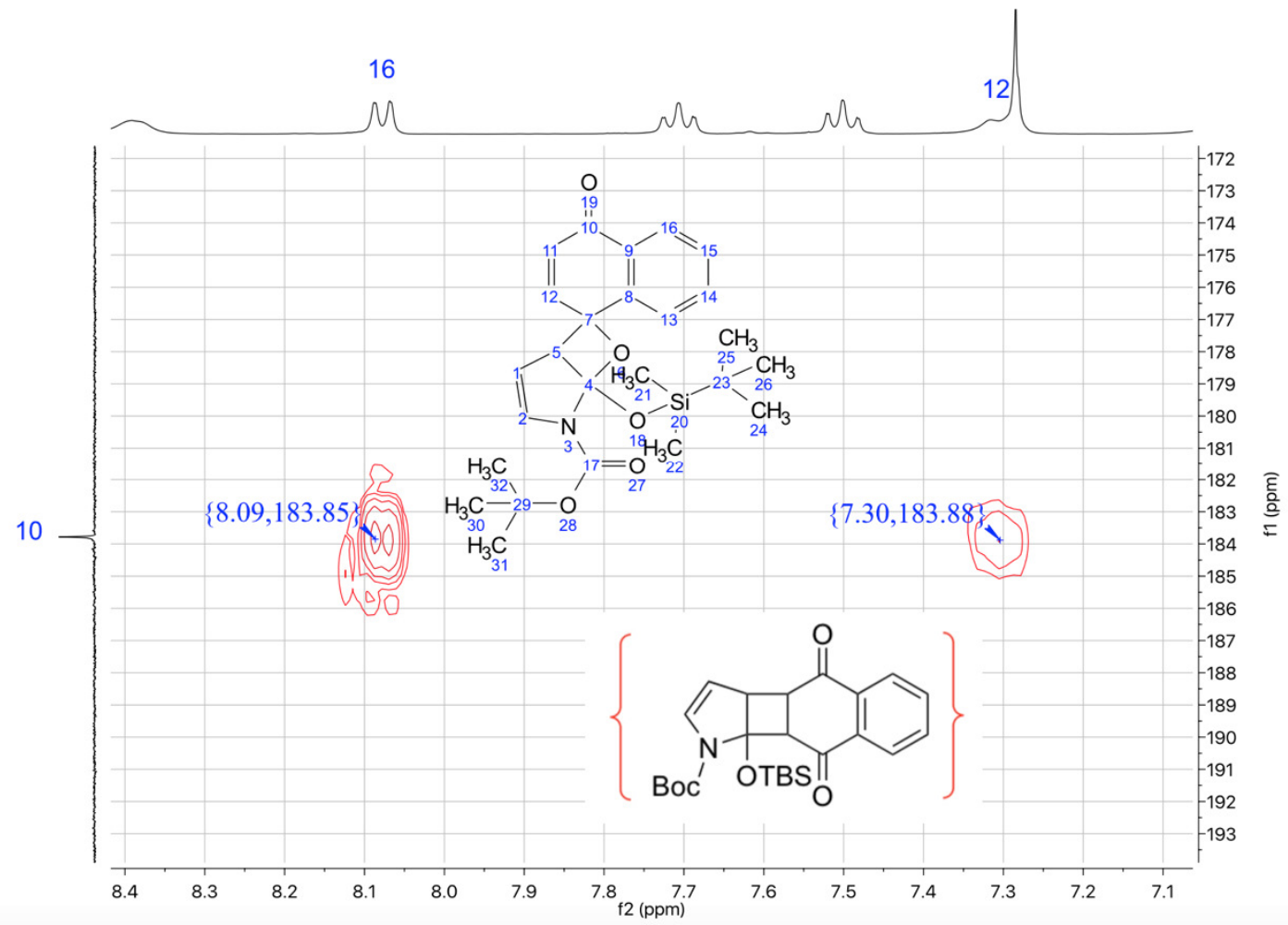

Figure 8. $\mathrm{H}-\mathrm{C} \mathrm{HMBC}$ spectrum of $8\left(400 \mathrm{MHz}, \mathrm{CDCl}_{3}\right)$.

The stereochemistry of compound 8 was determined to be exo, because the correlation of $\mathrm{H}_{5}(\delta 3.80)$ and $\mathrm{H}_{13}(\delta 8.39)$ was observed in the H-H NOESY spectrum (Figure 9). 


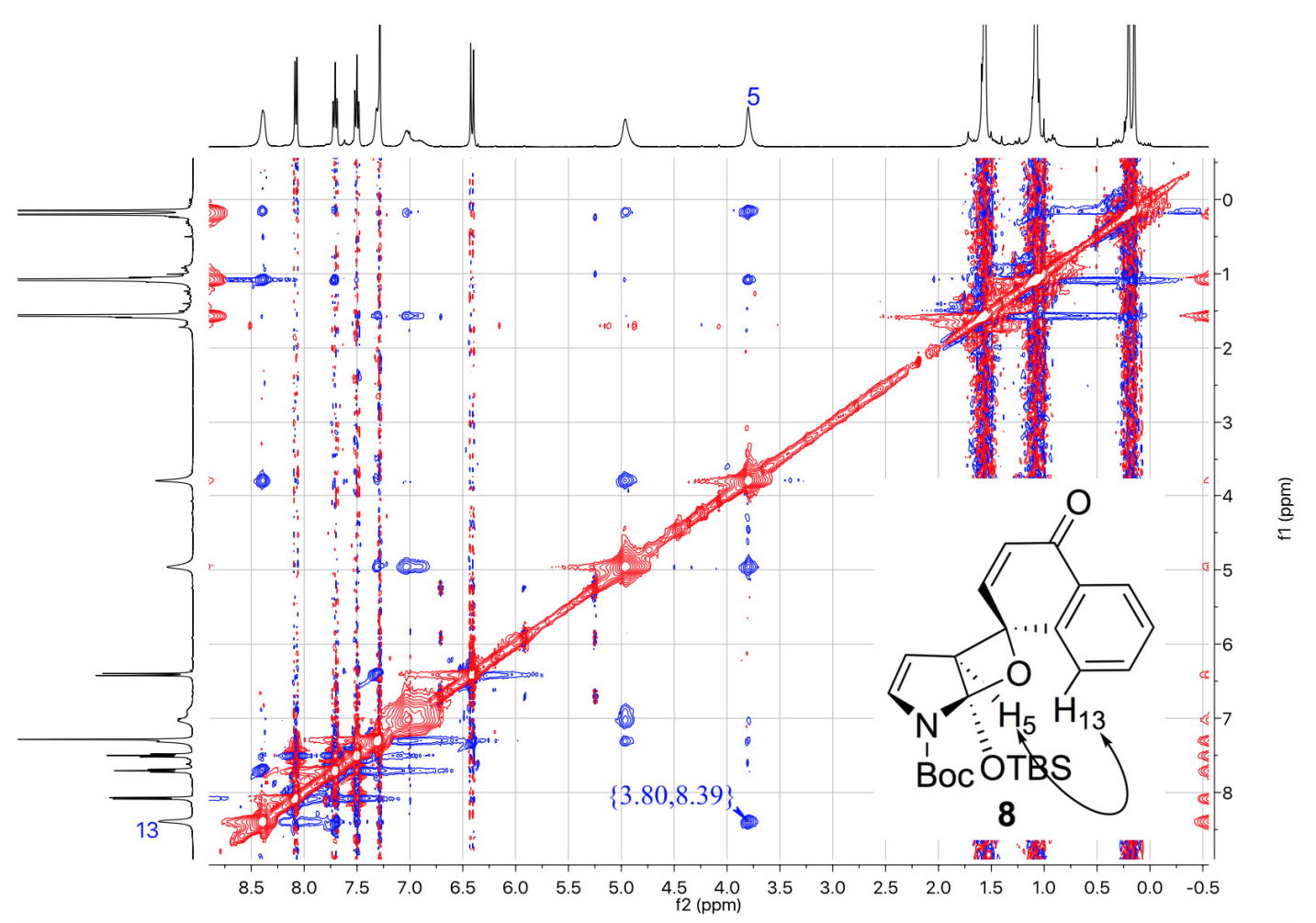

Figure 9. $\mathrm{H}-\mathrm{H}$ NOESY spectrum of 8. (400 $\left.\mathrm{MHz}, \mathrm{CDCl}_{3}\right)$.

\section{Conclusions}

In the present study, regio- and stereoselectivity of photochemical reaction of the pyrrole derivative 1 with two types of enone derivatives $\mathbf{4}$ or $\mathbf{5}$ were investigated in detail. In the reaction with cyclopentenone $\mathbf{4}$, exoselective formation of tricyclic cyclobutanes $\mathbf{5}$ and $\mathbf{6}$ was observed. In contrast to the selective formation of cyclubutane formation, the selective formation of oxetane was found in the reaction with naphthoquinone (5), although the reaction conversion was rather low. The mechanistic study based on the quantum chemical and spectroscopic investigation is now ongoing to clarify the dramatic effect of the enone derivative on the product selectivity.

\section{Experimental Section}

General. All the reagents and solvents were obtained at reagent grade and used without further purification. Thin layer chromatography (TLC) analysis was performed on silica gel plates and imagined under ultraviolet light. ${ }^{1} \mathrm{H}$ NMR and ${ }^{13} \mathrm{C}$ NMR data were recorded with an $400 \mathrm{MHz} N M R$ spectrometer. $\mathrm{CDCl}_{3}(0.03 \%$ TMS) was used as deuterated solvents. Chemical shifts were described in parts per million (ppm) relative to trimethylsilane $(\delta=0.00 \mathrm{ppm})$, and the coupling constants $(J)$ was stated in Hertz $(\mathrm{Hz})$. High-resolution Mass (HRMS) spectroscopic analyses were conducted using a Orbitrap XL instrument using the positive ion mode.

Starting material 1 was prepared by the reported method. ${ }^{43}$ 


\section{General procedure of the photoreaction of 1 and 4, 5}

a. [4] or [5] was $340 \mathrm{mM}$

The solution of starting material in Pyrex NMR tube was bubbled with nitrogen for 20 minutes. After irradiation (high pressure $\mathrm{Hg}$ lamp or $365 \mathrm{~nm}$ light-emitting diode), the reaction mixture was concentrated under reduced pressure. The desired product was purified by silica gel column chromatography (elution of EtOAc : Hexane $=1: 8)$.

\section{b. [4] or [5] was $42.5 \mathrm{mM}$}

The solution of starting material in test tube was degassed by freeze/pump/thaw 5 times. After irradiation (365 nm light-emitting diode), the reaction mixture was concentrated under reduced pressure. The desired product was purified by silica gel column chromatography (elution of EtOAc : Hexane = 1:8).

tert-Butyl 6b-((tert-butyldimethylsilyl)oxy)-4-oxo-3b, 4, 5, 6, 6a, 6b hexahydrocyclopenta [3,4]cyclobuta[1,2b]pyrrole-1(3aH)-carboxylate and tert-butyl 6b-((tert-butyldimethylsilyl)oxy)6-oxo-3b,4,5,6,6a,6b-hexahydrocyclopenta[3,4]cyclobuta[1,2-b]pyrrole-1(3aH)-carboxylate (6 and 7). Colourless oil. ${ }^{1} \mathrm{H} \mathrm{NMR}(400 \mathrm{MHz}$, $\left.\mathrm{CDCl}_{3}\right) \delta 6.80(\mathrm{~d}, J 4.4 \mathrm{~Hz}, 6-1 \mathrm{H}), 6.65(\mathrm{~d}, J 4.4 \mathrm{~Hz}, 7-1 \mathrm{H}), 5.20(\mathrm{t}, J 3.9 \mathrm{~Hz}, 6-1 \mathrm{H}), 5.13(\mathrm{~s}, 7-1 \mathrm{H}), 3.46(\mathrm{t}, J 7.7 \mathrm{~Hz}$, 7-1H), $3.30(t, J 7.9 \mathrm{~Hz}, 6-1 \mathrm{H}), 3.02(\mathrm{t}, J 2.9 \mathrm{~Hz}, 6-1 \mathrm{H}), 2.99-2.91(\mathrm{~m}, 7-1 \mathrm{H}), 2.72-2.41(\mathrm{~m}, 2 \mathrm{H}), 2.40-2.37(\mathrm{~m}$, $1 \mathrm{H}), 2.29(\mathrm{dd}, J 17.7,9.2 \mathrm{~Hz}, 1 \mathrm{H}), 2.11-1.90(\mathrm{~m}, 1 \mathrm{H}), 1.52(\mathrm{~s}, 9 \mathrm{H}), 0.93(\mathrm{~s}, 9 \mathrm{H}), 0.06(\mathrm{~d}, J 13.4 \mathrm{~Hz}, 6 \mathrm{H}) .{ }^{13} \mathrm{C} \mathrm{NMR}$ (101 MHz, CDCl ${ }_{3}$ ) $\delta 220.1$ (7), 219.7 (6), 151.7 (6), 149.9 (7), 132.74 (6), 132.69 (7), 107.6 (6), 107.3 (7), 89.7 (7), 89.3 (6), 81.0 (7), 80.9 (6), 55.8 (6), 55.0 (7), 48.4 (6), 47.4 (7), 46.4 (6), 46.3 (7), 36.4, 28.4, 25.7, 21.8 (7), $21.3(6), 17.9(7), 17.8(6),-3.9(6),-3.98(7),-4.02(6),-4.3(7)$. HRMS (ESI+) $\mathrm{m} / \mathrm{z}$ : [M+Na] ${ }^{+}$anal. calcd for $\mathrm{C}_{20} \mathrm{H}_{33} \mathrm{O}_{4} \mathrm{NNaSi} 402.20711$, found 402.20728.

tert-Butyl 1-((tert-butyldimethylsilyl)oxy)-4'-oxo-4'H-7-oxa-2-azaspiro[bicyclo[3.2.0]heptane-6,1'-naphthalen]-3-ene-2-carboxylate (8). Light yellow oil. ${ }^{1} \mathrm{H} \mathrm{NMR}\left(400 \mathrm{MHz}, \mathrm{CDCl}_{3}\right) \delta 8.39(\mathrm{~d}, J 7.5 \mathrm{~Hz}, 1 \mathrm{H}), 8.08(\mathrm{dd}, J$ 7.9, $1.5 \mathrm{~Hz}, 1 \mathrm{H}), 7.73-7.69(\mathrm{~m}, 1 \mathrm{H}), 7.51(\mathrm{dd}, J$ 7.6, $1.3 \mathrm{~Hz}, 1 \mathrm{H}), 7.32(\mathrm{~s}, 1 \mathrm{H}), 7.02(\mathrm{~d}, J 11.4 \mathrm{~Hz}, 1 \mathrm{H}), 6.41(\mathrm{~d}, J$ $10.4 \mathrm{~Hz}, 1 \mathrm{H}), 4.96(\mathrm{~s}, 1 \mathrm{H}), 3.80(\mathrm{~s}, 1 \mathrm{H}), 1.56(\mathrm{~s}, 9 \mathrm{H}), 1.08(\mathrm{~s}, 9 \mathrm{H}), 0.20(\mathrm{~s}, 3 \mathrm{H}), 0.15(\mathrm{~s}, 3 \mathrm{H}) .{ }^{13} \mathrm{C} \mathrm{NMR}(101 \mathrm{MHz}$, $\left.\mathrm{CDCl}_{3}\right) \delta 183.8,148.4,143.7,138.6,135.5,133.9,133.3,129.5,129.4,128.7,127.2,126.4,126.2,101.9,81.8$, $64.3,28.3,25.6,17.9,-4.15,-4.25$. HRMS $(E S I+) \mathrm{m} / \mathrm{z}$ : $[\mathrm{M}+\mathrm{Na}]^{+}$anal. calcd for $\mathrm{C}_{25} \mathrm{H}_{33} \mathrm{O}_{5} \mathrm{NNaSi} 478.20202$, found 478.20209.

\section{Supplementary Material}

${ }^{1} \mathrm{H},{ }^{13} \mathrm{C}$ and HRMS spectra of $\mathbf{6 , 7}$ and 8 and UV spectra of 4 and $\mathbf{5}$.

\section{References}

1. Crimmins, M. T.; Reinhold, T. L. Org. Reactions, 1993, 44, 297.

2. Hoffmann, N. Chem. Rev. 2008, 108, 1052. http://dx.doi.org/10.1021/cr0680336

3. Poplata, S.; Tröster, A.; Zou, Y. -Q.; Bach, T. Chem. Rev. 2016, 116, 9748. http://dx.doi.org/10.1021/acs.chemrev.5b00723

4. Hehn, J. P.; Müller, C.; Bach, T. Formation of a Four-Membered Ring: From a Carbonyl-Conjugated Alkene, in: Handbook of Synthetic Photochemistry Eds: A. Albini; M. Fagnoni Wiley-VCH, 2010, p 171. 
5. Eaton, P. E. Tetrahedron Lett. 1964, 5, 3695. https://dx.doi.org/10.1016/S0040-4039(01)89395-3

6. Jana, A.; Mondal, S.; Ghosh, S. Org. Biomol. Chem. 2015, 13, 1846. http://dx.doi.org/10.1039/c4ob02182g

7. Mascitti, V.; Corey, E. J. J. Am. Chem. Soc. 2006, 128, 3118. http://dx.doi.org/10.1021/ja058370g

8. Fukuda, Y.; Negoro, T.; Tobe, Y.; Kimura, K.; Odaira, Y. J. Org. Chem. 1979, 44, 4557. http://dx.doi.org/10.1021/jo00393a021

9. Schuster, D. I.; Lem, G.; Kaprinidis, N. A. Chem. Rev. 1993, 93, 3. http://dx.doi.org/10.1021/cr00017a001

10. Namyslo, J. C.; Kaufmann, D. E. Chem. Rev. 2003, 103, 1485. http://dx.doi.org/10.1021/cr010010y

11. Fu, N. Y.; Chan, S. H.; Wong, H. N. C. In Patai Series: The Chemistry of Functional Groups; Rappoport, Z., Series Ed.; Wiley: Chichester, 2005; The Chemistry of Cyclobutanes Part 1 Rappoport, Z., Liebman, J. F., Eds., p 357.

12. Horspool, W. In Patai Series: The Chemistry of Functional Groups; Rappoport, Z., Series Ed.; Wiley: Chichester, 2005; The Chemistry of Cyclobutanes Part 2 Rappoport, Z., Liebman, J. F., Eds., p 715.

13. Lee-Ruff, E.; Mladenova, G. Chem. Rev. 2003, 103, 1449. http://dx.doi.org/10.1021/cr010013a

14. Bach, T. Synthesis, 1998, 683. http://dx.doi.org/10.1055/s-1998-2054

15. Mattay, J.; Conrads, R.; Hoffmann, R. Methoden der Organischen Chemie (Houben-Weyl), 4th ed.; Helmchen, G., Hoffmann, R. W., Mulzer, J., Schaumann, E., Eds., Thieme Verlag: Stuttgart, 1996; Vol. 5 E21, p 3085.

16. Jana, A.; Mondal, S.; Hossain, M. F.; Ghosh, S. Tetrahedron Lett. 2012, 53, 6830. http://dx.doi.org/10.1016/i.tetlet.2012.10.018

17. Ohkita, M.; Sano, K.; Suzuki, T.; Tsuji, T.; Sato, T.; Niino, H. Org. Biomol. Chem. 2004, 2, 1044. http://dx.doi.org/10.1039/b400080n

18. Crimmins, M. T.; Pace, J. M.; Nantermet, P. G.; Kim-Meade, A. S.; Thomas, J. B.; Watterson, S. H.; Wagman, S. J. Am. Chem. Soc. 2000, 122, 8453.

http://dx.doi.org/10.1021/ja001747s

19. Winkler, J. D.; Bowen, C. M.; Liotta, F. Chem. Rev. 1995, 95, 2003.

http://dx.doi.org/10.1021/cr00038a010

20. Bach, T.; Hehn, J. P. Angew. Chem. Int. Ed. 2011, 50, 1000. http://dx.doi.org/10.1002/anie.201002845

21. Porco, J. A.; Schreiber, S. L. In Comprehensive Organic Synthesis; Trost, M. M. Ed; Pergamon Press: New York, 1991, Vol. 5, p 151.

22. Abe, M. J. Chin. Chem. Soc. 2008, 55, 479. http://dx.doi.org/10.1002/jccs.200800072

23. Abe, M. Formation of a 4-Membered ring: Oxetanes, in: Handbook of Synthetic Photochemistry (Eds: A. Albini; M. Fagnoni), Wiley-VCH, 2010, p 217.

24. Ciamician, G.; Silber, P. Ber. Dtsch. Chem. Ges. 1908, 41, 1928.

http://dx.doi.org/10.1002/cber.19080410272

25. Paternò, E.; Chieffi, G. Gazz. Chim. Ital. 1909, 39, 341. 
26. Elliott, L. D.; Berry, M.; Orr-Ewing, A. J.; Booker-Milburn, K. I. J. Am. Chem. Soc. 2007, 129, 3078. http://dx.doi.org/10.1021/ja070254l

27. Maskill, K. G.; Knowles, J. P.; Elliott, L. D.; Alder, R. W.; Booker-Milburn, K. I. Angew. Chem. Int. Ed. 2013, 52, 1499.

http://dx.doi.org/10.1002/anie.201208892 .

28. Koovits, P. J.; Knowles, J. P.; Booker-Milburn, K. I. Org. Lett. 2016, 18, 5608. http://dx.doi.org/10.1021/acs.orglett.6b02829

29. Rivas, C.; Bolívar, R. A. J. Heterocyclic Chem. 1976, 13, 1037. http://dx.doi.org/10.1002/ihet.5570130520

30. Guilford, J.; Helmuch, M. G.; Julie, L. J. Org. Chem. 1979, 44, 2949. http://dx.doi.org/10.1021/jo01330a03031

31. Oda, K.; Machida, M.; Aoe, K. Chem. Pharm. Bull. 1986, 34, 1411.

http://dx.doi.org/10.1248/cpb.34.3142

32. Sano, T.; Enomoto, H.; Kurebayashi, Y.; Horiguchi, Y.; Tsuda, Y. Chem. Pharm. Bull. 1993, 41, 471. http://dx.doi.org/10.1248/cpb.41.471

33. Wrobel, M. N.; Margaretha. Helv. Chim. Acta. 2003, 86, 515. http://dx.doi.org/10.1002/hlca.200390051

34. Elliott,L. D.; Knowles, J. P.; Koovits, P. J.; Maskill, K. G.; Ralph, M. J.; Lejeune, G.; Edwards, L. J.; Robinson, R. I.; Clemens, I. R.; Cox, B.; Pascoe, D.D.; Koch, G.; Eberle, M.; Berry, M. B.; Booker-Milburn, K. I. Chem. Eur. J. 2014, 20, 15226. http://dx.doi.org/10.1002/chem.201404347

35. Ikeda, M. Chem. Soc., Perkin Trans. 1, 1984, 405. http://dx.doi.org/10.1039/P19840000405

36. Winkler, J. D.; Scott, R. D.; Williard, P. G. J. Am. Chem. Soc. 1990, 112, 8971. http://dx.doi.org/10.1021/ja00180a049

37. Hastings, D. J.; Weedon, A. C. J. Org. Chem. 1991, 56, 6326. http://dx.doi.org/10.1021/jo00022a021

38. Hastings, D. J.; Weedon, A. C. Tetrahedron Lett. 1991, 32, 4107. http://dx.doi.org/10.1016/S0040-4039(01)88628-7

39. Oldroyd, D. L.; Weedon, A. C. J. Chem. Soc., Chem. Commun. 1992, 1491. http://dx.doi.org/10.1039/C39920001491

40. Oldroyd, D. L.; Payne, N. C.; Vittal, J. J.; Weedon, A. C.; Zhang, B. Tetrahedron Lett. 1993, $34,1087$. http://dx.doi.org/10.1016/S0040-4039(00)77497-1

41. Martin, V. I.; Goodell, J. R.; Ingham, O. J.; Porco, Jr. J. A.; Beeler, A. B. J. Org. Chem. 2014, 79, 3838. http://dx.doi.org/10.1021/jo500190b

42. Xue, J.; Abe, M.; Takagi, R. J. Phys. Org. Chem. 2017, 30, e3632. http://dx.doi.org/10.1002/poc.3632

43. Curti, C.; Ranieri, B.; Battistini, L.; Rassu, G.; Zambrano, V.; Pelosi, G.; Casiraghi, G.; Zanardi, F. Adv. Synth. Catal. 2010, 352, 2011.

http://dx.doi.org/10.1002/adsc.201000189

44. Horspool, W. M. "Enone Cycloadditions and Rearrangements: Photoreactions of Dienones and Quinones" in Specialist Periodical Report on Photochemistry, The Royal Society of Chemistry, Cambridge, 1970-1999, vol. 1-30. 
45. Maruyama K.; Osuka, A. "Recent Advances in the Photochemistry of Quinones," in The Chemistry of Quinonoid Compounds, vol. II, ed. S. Patai and Z. Rappoport, Wiley, New York, 1988; Ch. 13. http://dx.doi.org/10.1002/9780470772119

46. Bryce-Smith, D.; Evans, E. H.; Gilbert, A.; McNeill, H. S. J. Chem. Soc., Perkin Trans 1, 1992, 485. http://dx.doi.org/10.1039/P19920000485

47. Ochiai, M. ; Arimoto, M. ; Fujita, E. J. C.S., Chem. Comm. 1981, 460. http://dx.doi.org/10.1039/C39810000460

48. Yoshizawa, M.; Takeyama, Y.; Okano, T.; Fujita, M. J. Am. Chem. Soc. 2003, 125, 3243. http://dx.doi.org/10.1021/ja020718+

49. Yoshizawa, M.; Takeyama, Y.; Kusukawa, T.; Fujita, M. Angew. Chem. Int. Ed. 2002, 41, 1347. http://dx.doi.org/10.1002/1521-3773(20020415)41:8<1347::AID-ANIE1347>3.0.CO;2-X

50. Wang, W.; Zhang, W. -J.; Wang, L.; Quah, C. K.; Fun, Hoong. -K.; Xu, J. -H.; Zhang, Y. J. Org. Chem. 2013, $78,6211$. http://dx.doi.org/10.1021/jo4008767 